\title{
Does Grammatical Accuracy Affect Request Strategy Use?
}

\author{
I Nyoman Suka Sanjaya, I Made Ardana Putra, Anak Agung Raka Sitawati, and Ni Ketut Suciani \\ Dept. of Business Administration \\ Bali State Polytechnic \\ Bali, Indonesia \\ suka.sanjaya@gmail.com
}

\begin{abstract}
The present study was aimed at examining whether grammatical accuracy was a significant predictor of use of request strategy (direct or indirect) in second language performance. Participants were 39 seventh semester students (29 males and 10 females) majoring in International Business Management at one public higher education institution in Bali. Their English proficiency levels ranged from pre-intermediate to intermediate. The participants were asked to write an e-mail based on a situation carefully designed so as to necessitate the use of indirect strategy. Grammatical accuracy was operationalized as average score per $T$-unit. The head act of each request was coded as either direct or indirect. Binary logistic regression was conducted on the data with significance level being set at $p<.05$. The result revealed that grammatical accuracy was not a significant predictor of request strategy use (Wald $=0.00, \mathrm{df}=1$, $\mathbf{p}=\mathbf{0 . 9 6}$ ). This result indicates that the odds for using indirect strategy are similar regardless of level of levels of grammatical accuracy.
\end{abstract}

Keywords: grammatical accuracy, interlanguage request strategy, Indonesian learners, pragmatic competence

\section{INTRODUCTION}

Pragmatic competence refers to the ability to use language appropriately and effectively in a particular context [1]. An EFL (English as a foreign language) learner can be considered pragmatically competent in English if he or she has the knowledge of linguistic resources available in English that can be used to decode and encode a particular illocutionary intent, as well as knowledge of sociocultural conventions pertaining to appropriate use of those linguistic resources [2]. These two distinct, yet seemingly interrelated knowledge bases making up the concept of pragmatic competence, namely linguistic and sociocultural knowledge, are widely known as pragmalinguistic and sociopragmatic knowledge, respectively [3]. For more recent discussion of pragmalinguistics and sociopragmatics, see [4] and [5], respectively. Compared to other aspects of communicative competence [6], pragmatic competence constitutes the most important aspect, since inappropriate use of language can potentially lead to unfortunate, or even dire, consequences [7, 8].

Research into interlanguage pragmatics has predominantly focused on speech acts, and requests have been the most researched speech act [9]. This may be triggered by the fact that enlisting assistance from others is one of the most frequently performed verbal acts in social interaction [10], and consequently mastery of such speech act by EFL learners is inevitable. Unfortunately, the majority of those studies have focused on oral mode [9, 11], leaving the written mode relatively underexplored. Indeed, a number of studies have been carried out to examine learners' pragmatic ability in composing e-mail requests. However, such studies have largely been descriptive and comparative in nature, merely describing the strategies and modification used by the learners, and subsequently comparing them with those used by native speakers [12-17], or describing the cognitive process involved while learners are writing an e-mail [18]. Classroom experimental research by and large has examined the efficacy of instruction on the acquisition of pragmatic ability in writing e-mails [19-22].

The issue of whether grammatical competence can have a significant influence on pragmatic competence has not generated serious attention from researchers [23], despite its importance in the field of interlanguage pragmatics [24]. Indeed, research into interlanguage pragmatics has begun to address the interrelationship between the two components of communicative competence. Yet, the findings have been inconsistent; some researchers found that grammatical and pragmatic competence are not interrelated, that is, the two types of competence develop independently of each other [2528], while others [29-31] showed that there exists an interface between them. Such conflicting findings warrant further exploration. Moreover, the extent to which knowledge of grammatical accuracy can predict use of interlanguage request strategy has not been explored. Consequently, to what extent learners having higher grammatical accuracy tend use a request strategy different than that used by learners having lower grammatical accuracy still constitutes a mystery.

A request can be defined as an illocutionary act whereby a speaker gets a hearer to perform an act at the cost to the hearer but for the benefit of the speaker [32].By its very nature, then, request is inherently an impositive act since asking someone to do something means imposing on him or her in one way or another; through a request the speaker is getting the requestee to do something that he or she would not otherwise do. This is the reason why request is considered an FTA(face-threatening act)[33]. Given the fact that a request is inevitably impositive in nature, the act of requesting therefore constitutes a daunting 
task on the part of the requester, and as such it requires to be executed with particular tact and consideration, so as to avoid unnecessary offence to the requestee. When doing an FTA, the speaker could employ a set of strategies[33], ranging from direct strategies (e.g. Give me the book) or indirect ones (e.g. I was wondering if you could give me the book).

The question which arises now is that whether EFL learners' knowledge of grammatical accuracy can influence their use of request strategy in a particular context. The present study was carried out to explore such an issue.The main purpose of the study was to examine whether level of grammatical accuracy was a significant predictor of request strategy use. To be more exact, the study was conducted to specifically delve into the extent to which learners with higher level of grammatical accuracy used indirect strategy, while those with lower level of grammatical accuracy used direct strategy in their e-mail, in response to a situational context in which the use of indirect strategy was necessary, indicating that the learners with higher grammatical accuracy were more pragmatically competent than their fellow learners with lower grammatical accuracy. The present study was guided by the following research question: "Can request strategy use be significantly predicted by grammatical accuracy”?

\section{METHOD}

\section{A. Participants}

Forty seventh semester students (29 females and 11 males), between the ages of 21 and 22 years, agreed to participate in the present study. They were enrolled in a fouryear undergraduate program in International Business Management in one medium size public higher education institution located in southern Bali. Since they had not taken any standardized English proficiency test, such as TOEFL, IELTS, or TOEIC, it was not possible to determine their formal level of English proficiency. However, according to their English instructor, on the basis of his informal observation in class, their English proficiency level ranged from pre-intermediate to intermediate, with the majority of them falling into the former.

At the time the study was conducted (November 2016), the research participants received 150 minutes of English instruction per week. It is important to note that they had not been studying English pragmatics. None of the participants reported to have lived or visited an English speaking country. They were deliberately told that they participated in a research on business e-mail writing, and they expressed agreement to participate. However, the specific aim of the study was not disclosed to them.

\section{B. Instrument and Procedure}

The instrument used to gather the data analyzed in the present study took the form of a written test in which the research participants had to write an e-mail in response to a particular situational scenario depicting a workplace business communication (see appendix). Given the fact that they were majoring in International Business Management, it could be argued that they were fully familiar with the scenario. The situation was carefully designed so as to elicit the target speech act (i.e. request) and include the following contextual characteristics: (i) the power difference between the e-mail writer and the recipient was large whereby the power of the latter was much higher than that of the former; (ii) social distance between the e-mail writer and recipient was large; and finally, (iii) the request sounded highly impositive. As such, the situation described a condition wherein the FTA created by the request was serious or weighty. Such condition, from the perspective of English culture, requires that the request is executed using indirect strategy [33]. Finally, the language of the scenario was English, but attempt was made to ensure that it was within their comprehension level to ensure that it was easy to understand.

Before the test was administered the participants were informed that the test was a data gathering session and that their writing would be used for publication purposes, and all of them consented. The test was a paper-and-pencil test and was not timed. It was administered strictly to ensure the validity (i.e. independence) of the resulting data. The participants were allowed to ask questions during the test administration as long as those questions were related to the scenario, but not to the English language, such as vocabulary, grammar. In fact, none of the students asked any question, indicating that the language of the scenario was within their comprehension level and the scenario was free from ambiguity. The time needed by the participants to complete the test ranged from 20 to 30 minutes. Upon completion of the test, the participants were subsequently consulted through focus group discussion regarding the characteristics of the situation used in the research instrument. This was done to see the extent to which the participants' perception of the situation used in the test corroborated that of the researcher. In general, they agreed that the imposition associated with the request was great, that their relationship with the recipient was distant, and that the recipient's power was great relative to theirs.

\section{Data Analysis}

The present paper presents a bivariate study of the effect of grammatical accuracy on request strategy use. As such, there is one predictor variable, namely grammatical accuracy (a continuous variable) and one outcome variable, namely request strategy (a dichotomous variable: direct or indirect). The unit of analysis for the predictor variable isT-unit (i.e. minimal terminable unit) defined as "the shortest unit ... which a sentence can be reduced to, and consisting of one main clause with all subordinate clauses attached to it" [34]. Each of the e-mail requests were broken down into T-units, and each T-unit was scored following the scoring rubric as shown in Table 1.

Segmentation of the e-mails into their T-units did not include the salutation (e.g. Dear Mr. Blunder), and hence they were not assigned any accuracy score. It could be argued that through the use of such salutation, students did not necessarily demonstrate their knowledge of grammatical accuracy. It should be stressed that grammatical errors analyzed in the present study included not only syntactic errors (e.g.Tomorrow 
I am have a job to send a parcel ...), but also morphological ones (e.g. I can driving). Other errors (e.g. spelling errors, punctuation errors) were excluded from the analysis, since those errors cannot be regarded as having anything to do with grammatical accuracy. Grammatical accuracy score for one email was computed by averaging the scores of all T-units making up the e-mail in question.

The unit of analysis for the outcome variable was the individual e-mail. The definition of request strategy adopted in the present study is as follows: "the communicative means we use when trying to get someone to do something they would probably not do of their own accord" [8]. Each e-mail was first independently segmented to delimit the request head act, defined as that segment of the e-mail "that constitutes the nucleus of the speech act ... i.e. that part of the sequence which might serve to realize the act independently of other elements" [35]. The request strategy of the head act contained in each e-mail was then coded in terms of its strategy, as either direct or indirect, based on the framework deployed in the study conducted by Blum-Kulka and Olshtain [35]. It is to be borne in mind that the analytical framework used by BlumKulka and Olshtain [35] comprised of three types of request strategy, namely direct, conventionally indirect, and hints. In the present study, conventionally indirect strategy and hint, following their practice, were grouped into indirect strategy. Table 2 presents the request strategy coding scheme used in the present study (examples were taken from data for the present study).

TABLE 1. SCORING RUBRIC FOR GRAMMATICAL ACCURACY

\begin{tabular}{|c|c|}
\hline Score & Remarks \\
\hline 4 & T-Unit contains no grammatical error \\
\hline 3 & T-unit contains one grammatical error \\
\hline 2 & T-unit contains two grammatical errors \\
\hline 1 & T-unit contains more than two grammatical errors \\
\hline
\end{tabular}

TABLE 2. REQUEST STRATEGY CODING SCHEME

\begin{tabular}{|c|c|c|}
\hline Strategy & Description & Example \\
\hline \multicolumn{3}{|l|}{ A.Direct } \\
\hline Want & $\begin{array}{l}\text { The writer explicitly expresses his or her } \\
\text { request through want or would like }\end{array}$ & $\begin{array}{l}\text { We would like to borrow your car which is } \\
\text { available in our company }\end{array}$ \\
\hline Need & $\begin{array}{l}\text { The writer expresses his desire to make a } \\
\text { request through need }\end{array}$ & I need to borrow one of your car? \\
\hline Performative & $\begin{array}{l}\text { The communicative intent is marked } \\
\text { explicitly through a performative verb. }\end{array}$ & $\begin{array}{l}\text { My aim in writing this e-mail is to ask } \\
\text { permission to use your car }\end{array}$ \\
\hline \multicolumn{3}{|l|}{ B. Indirect } \\
\hline Preparatory & $\begin{array}{l}\text { The communicative intent is conventionally } \\
\text { expressed through a preparatory condition. }\end{array}$ & May I borrow your car? \\
\hline Hint & $\begin{array}{l}\text { The communicative intent is indirectly stated } \\
\text { through a hint. }\end{array}$ & I hope you can help me to provide a car. \\
\hline
\end{tabular}


To answer the research question, the data were statistically analyzed using binary logistic regression, with the significance level (p) being set at $p<.05$. Binary logistic regression is used when the outcome variable is dichotomous (i.e. has only two categories) and the predictor variable can be either interval or categorical, or both [36, Chapter 5]. All statistical analyses were conducted with the help of SPSS (Statistical Package for the Social Sciences) version 23.

\section{FINDING AND DISCUSSION}

Table 3 below shows the descriptive statistics of grammatical accuracy scores. It should be reiterated that the lowest score that a participant could obtain was 1 , while the highest (i.e. perfect) score was 4.0. It was found that the minimum score was 1.7 obtained by only one participant ( $2.5 \%$ of the total participants), whereas the perfect score was obtained by three participants ( $7.5 \%$ of the total participants). In fact, 1.7 was an outlier, that is, a value very different from other values in the present study [37]. Therefore, it would seem reasonable to argue that the participant with the accuracy score of 1.7 was exceptionally poor in his or her knowledge of grammatical accuracy relative to other participants in the present study. With an average score of 3.31 (out of the highest average score of 4.0), it is reasonable to argue that the participants in the present study were relatively grammatically competent, as far as grammatical accuracy was concerned. The magnitude of the standard deviation (0.45) relative to the mean value of 3.31 indicated that the mean was a good fit to the observed data, or in other words the mean was quite representative of the observed data. To put it in less technical terms, the participants in the present study appeared to be uniform in terms of their knowledge of grammatical accuracy. That is, on average, each participant's score deviated from the sample mean by less than half a point. Finally, the relatively small size of the standard error of the mean suggested that the sample of the present study could be considered as defensibly representative of the target population (i.e. English language learners studying in a foreign language learning context). A standard error of 0.71 shows that should infinite samples be drawn from the same population as that from which the sample of the present study was drawn, on average the mean of each of those infinite samples would differ from the mean of the population by only 0.71 .

Several e-mails contained more than one request, one of which served as the main request (i.e. request to borrow the car), which was usually found in the head act of each e-mail, while the other was a secondary one (e.g. request to get a prompt reply). For example, the following two requests were identified in the same e-mail: I would like to ask your permission to allow me to use your car to send the parcel and Please reply my e-mail as soon as possible. In this particular instance, only the former is clearly a request to borrow a car. The practice adopted in the present study, due to the nature of the statistical procedure followed, was that only the main request was included in the analysis. It is to be borne in mind that the aim of the present study was to examine whether knowledge of grammatical accuracy could significantly predict request strategy use (direct or indirect). Thus, including all request strategies identified in an e-mail would not achieve the aim, since two or more request strategies used in an e-mail could belong to both strategies (direct and indirect). Table 4 below shows the frequency of use of the two types of request strategy. As can be seen from table 4 , the number of participants who preferred to use indirect strategy was similar to the number of participants who preferred to use direct strategy. Table 5 presents the frequency of use of substrategies (want, need, performative, preparatory, and hint) within each of the two major strategies (direct and indirect).

TABLE 3. DESCRIPTIVE STATISTICS FOR GRAMMATICAL ACCURACY SCORE

\begin{tabular}{|l|c|c|c|c|c|c|}
\hline \multirow{2}{*}{$\begin{array}{l}\text { Grammatical } \\
\text { Accuracy }\end{array}$} & $\mathbf{N}$ & Minimum & \multirow{2}{*}{ Maximum } & \multicolumn{2}{|c|}{ Mean } & \multirow{2}{*}{$\begin{array}{c}\text { Std. } \\
\text { Deviation }\end{array}$} \\
\cline { 5 - 7 } & 40 & 1.70 & 4.00 & 3.31 & 0.71 & 0.45 \\
\hline
\end{tabular}

TABLE 4. FREQUENCY OF MAJOR REQUEST STRATEGY TYPES

\begin{tabular}{|c|c|c|c|c|c|c|}
\hline \multirow{3}{*}{ RequestStrategy } & \multicolumn{2}{|c|}{ Direct } & \multicolumn{2}{c|}{ Indirect } & \multicolumn{2}{c|}{ Total } \\
\cline { 2 - 7 } & $n$ & $\%$ & $n$ & $\%$ & $n$ & $\%$ \\
\cline { 2 - 7 } & 20 & 50 & 20 & 50 & 40 & 100 \\
\hline
\end{tabular}


TABLE 5. FREQUENCY OF USE OF SUB-STRATEGIES

\begin{tabular}{|c|c|c|}
\hline Request Strategies & $\mathbf{n}$ & \% \\
\hline Direct & 20 & 50 \\
\hline Want & 10 & 25 \\
\hline Need & 7 & 17.5 \\
\hline Performative & 3 & 7.5 \\
\hline Indirect & 20 & 50 \\
\hline Preparatory & 18 & 45 \\
\hline Hint & 2 & 5 \\
\hline Total & 40 & 100 \\
\hline
\end{tabular}

Within the major category of direct strategy, the substrategy want was the most preferred $(50 \%, \mathrm{n}=10)$, followed by need $(35 \%, \mathrm{n}=7)$ and performative $(15 \%, \mathrm{n}=3)$. Within the category of indirect strategy, the sub-strategy preparatory predominated $(90 \%, \mathrm{n}=18)$, while the sub-strategy hint was used with much smaller frequency $(10 \%, \mathrm{n}=2)$.

Tests of assumptions of logistic regression were conducted to examine whether the data met those assumptions. The results showed evidence of noncollinearity, as indicated by a tolerance value of 0.95 and a VIF (Variance Inflation Factor) value of 1.06. Tolerance value less than 0.10 and VIF value greater than 10 indicate multicollinearity [36]. Thus, the assumption of noncollinearity was met in the present study. The assumption of linearity was also met, as shown by the statistically non-significance of the interaction term of the continuous variable (i.e. grammatical accuracy) and its natural $\log , \mathrm{B}=-0.36, \mathrm{SE}=0.44$, Wald $=0.69, \mathrm{df}=1, \mathrm{p}=0.41$. The assumption of independence of errors was also met in the present study. Field [37] states that independence of errors "means that cases of data should not be related; for example, you cannot measure the same people at different points in time". In the present study, no two cases were related to each other since none of the participants were asked to write an email more than once. In a nutshell, the data in the present study met all classic assumptions of the statistical procedure employed, and thus the statistical results yielded should, to some extent, be valid.

The results showed that the baseline logistic regression model (i.e. the model that resulted from including only the constant) generated by SPSS to best fit the observed data in the present study predicted that all participants, regardless of level of grammatical accuracy, used indirect strategy and, as can be expected, such model correctly classified $50 \%$ of all participants, but misclassified the other $50 \%$. The $-2 \mathrm{Log}-$ likelihood of this baseline model was 55.45. The statistical result also revealed that the coefficient for the covariate not included in the baseline model (i.e. grammatical accuracy) was not different from zero, as shown by the value of the residual chi-square statistic, $\chi^{2}=.00, \mathrm{df}=3, \mathrm{p}=0.96$. This means that the addition of the predictor variable to the regression model would not make any difference. That is, it would not significantly contribute to (i.e. improve) the predictive power of the baseline model. In fact, the addition of the predictor variable to the baseline model did not result in improved classification accuracy of the new model (50\%). Recall that before the predictor variable was added to the model the classification accuracy was also $50 \%$. This was confirmed by the overall fit of the new model (i.e. when the predictor variable was included): $-2 \log$ likelihood $=55.45$, Cox and Snell $\mathrm{R}^{2}=0.00$; Nagelkerke $\mathrm{R}^{2}=0.00$. Notice exactly same value of $-2 \log$ likelihood before the predictor variable was included into the model. This again serves to confirm that the predictor variable in the present study (i.e. grammatical accuracy) did not have any effect on the probability of indirect request strategy being used in a situation wherein such strategy is the norm. Also notice the null effect size of the predictor variable (Cox and Snell $\mathrm{R}^{2}=$ 0.00 ; Nagelkerke $\mathrm{R}^{2}=0.00$ ).

Table 6 below provides further confirmation of the nonsignificant contribution of the predictor variable in the present study (grammatical accuracy) to the probability of indirect strategy being used. The table shows that every one-unit increase in grammatical accuracy would result in a decrease in the logit (i.e. natural logarithm) of indirect strategy by 0.03 unit. Again, this indicated that knowledge of grammatical accuracy was not a significant predictor of use of indirect strategy in situation where such strategy was necessary. In fact, knowledge of grammatical accuracy brought about an adverse impact on the use of indirect strategy (Recall the negative association between grammatical accuracy and use of indirect strategy). The table also shows that the odds of a learner with a higher knowledge of grammatical accuracy using indirect strategy were $97 \%$ (0.97 times) lower than those of a learner with lower knowledge of grammatical accuracy. Unfortunately, this statistical result did not reach significance at $\mathrm{p}<.05$. 
TABLE 6. VARIABLE IN THE EQUATION

\begin{tabular}{|c|l|c|c|c|c|c|c|c|c|}
\hline \multicolumn{2}{|c|}{} & \multirow{2}{*}{ B } & \multirow{2}{*}{ SE } & \multirow{2}{*}{ Wald } & \multirow{2}{*}{ df } & \multirow{2}{*}{ Sig. } & \multirow{2}{*}{$\operatorname{Exp}(\mathbf{B})$} & \multicolumn{2}{|c|}{$\begin{array}{c}\text { 95\% C.I. for } \\
\text { EXP(B) }\end{array}$} \\
\hline & & & & & & & & Lower & Upper \\
\hline \multirow{2}{*}{ Step } & Grammatical Accuracy & -.03 & 0.71 & .00 & 1 & 0.96 & 0.97 & 0.24 & 3.92 \\
\cline { 2 - 11 } & Constant & 0.11 & 2.40 & .00 & 1 & 0.96 & 1.12 & & \\
\hline
\end{tabular}

Now, to return to our research question presented in the introductory section, on the basis of the data obtained in the present study presented above, it appeared that knowledge of grammatical accuracy was not a significant predictor of request strategy use, in the sense that a learner with higher grammatical accuracy knowledge would not use indirect request strategy in a situational context wherein such strategy was the norm, compared to that with lower grammatical accuracy knowledge. To put it in different terms, learners with higher level of grammatical accuracy did not have a concomitant higher level of pragmatic ability. This is tantamount to saying that grammatical competence does not positively affect pragmatic competence.

The finding of the present study suggests that the development of pragmatic competence does not require prior development of grammatical competence, and as such, it is consistent with the finding of a three-year longitudinal case study conducted by Richard Schmidt [27]. Wes, the participant in the Schmidt study, displayed an impressive development of his ability to use English appropriately, or in other words, his pragmatic ability developed significantly during his three-year stay in Hawai'i. At the other extreme, his grammatical proficiency showed stagnation, in the sense that it remained rudimentary. The present study also provides important empirical evidence in support of the contention made by Bardovi-Harlig [38] that "a learner of high grammatical proficiency will not necessarily possess concomitant pragmatic competence." The development of grammatical competence does not seem to go hand in hand with that of pragmatic competence for adult L2 learners, accordingly. In particular, it seems that grammatical competence cannot accelerate the development of pragmatic competence, as the two types of competence appear to take different developmental paths. This is because the nature of grammatical development is quite different from that of pragmatic development in adult L2 acquisition [39]. That grammatical and pragmatic competence are independent of each other is quite surprising given the two types of competence make up the concept of 'communicative competence.' However, it sheds some light on the importance of the two types of competence. It may be that grammatical and pragmatic competence do not carry the same weight when it comes to effective communication. Wes in the Schmidt study was considered as an effective communicator by his native speaker interlocutors despite his apparently defective grammatical competence.
However, the finding of the present study contradicts that of the study carried out by Celaya and Barón [29]. In the Celaya and Barón study, learners of higher grammatical level were found to use indirect strategies compared to those of lower grammatical level. There are at least two factors which may account for such contradiction. First, the way the concept 'grammatical competence' was operationalized in the present study was different from that in Celaya and Barón's study. In the present study, it was confined to only grammatical accuracy, whereas in the Celaya and Barón study it included not only grammatical accuracy, but also grammatical complexity. In other words, grammatical competence in the present study was defined narrowly than in the Celaya and Barón study. Second, the size and characteristics of the participants involved in the two studies were apparently different. The present study involved many fewer participants than the Celaya and Barón study, 40 versus 144, respectively. In the present study the participants were uniform in terms of their ages, whereas in the Celaya and Barón study the participants were quite varied, between the ages of 10 and 18 .

The present study produced empirical evidence suggesting that it is possible for learners to gain pragmatic competence without gaining grammatical competence first. Admittedly, this sounds counterintuitive, as some people might believe that "in order to do things with words in a target language, the 'words' - used synecdochically for the grammar - must already be in place" [40]. Gaining pragmatic competence without gaining advanced grammatical competence first does not necessarily mean that learners can be pragmatically competent in English even though they have zero mastery of English grammar. Of course, zero mastery of grammar implies that any string of words might be incomprehensible. It is difficult to imagine a situation where a learner with no knowledge of English grammar at all can make a pragmatically meaningful verbal (i.e. linguistic) expression. That it is possible for learners to gain pragmatic competence without gaining grammatical competence first means that to be pragmatically competent learners do not need to wait until their grammatical competence reaches advanced level. Even basic or rudimentary grammatical proficiency can do the job quite well, when it comes to using language according to social norms or conventions. Wes in the Schmidt study mentioned above managed to successfully issue requests (e.g. maybe curtain $=$ 'maybe you should open the curtain'), despite his apparently undeveloped grammatical competence. This may 
simply be by virtue of the fact that adult second language (L2) speakers may not need to resort to their knowledge of grammar when they need to convey an illocutionary intent. Rather, they make use of their first language pragmatic competence. As astutely argued by Kecskes [39], L2 pragmatic skills "appear like modifications, adjustments and additions to the existing L1-based pragmatic competence." This may explain why learners in the present study were not different in terms of their use of request strategy regardless of the differences in grammatical competence. It may be the case that when responding to the situation given in the present study the learners were drawing upon their Indonesian-based pragmatic competence.

Related to the issue of L2 speakers' not relying on grammar resources when conveying an illocutionary intent is the fact that listeners do not likewise merely rely on grammatical features of utterances to extract the pragmatic meaning embedded in the utterances. Extra-linguistic context may play a more significant role in pragmatic inference. As in the words of King and Holmes [41], "a great deal of pragmatic inference is understood via a combination of language, tone, gesture, gaze, spatial orientation, embodiment, and facial expression as well as myriad other nonverbal means."

\section{CONCLUSION AND SUGGESTION}

The above-mentioned finding boils down to the seemingly valid conclusion that pragmatic competence may not be determined by grammatical competence. This further carries the implication that grammatical and pragmatic competence appear to develop independently of each other (i.e. the development of pragmatic competence does not rely on the development of grammatical competence), or in other words they take different paths of development. Admittedly, this conclusion should be treated with caution due to the small size of the sample of the present study. That relatively few participants involved $(\mathrm{N}=40)$ is apparently the major drawback of the present study. Therefore, it is suggested that future studies should be conducted with a much larger sample size. In so doing, confidence in conclusions derived from statistical procedures could no doubt be greatly enhanced.

Putting aside the drawback of the present study, the findings of the present study pedagogically implies that development of pragmatic competence in a second or foreign language cannot be accelerated through grammar teaching. To put it in different terms, equipping learners with ability to use language according to social conventions might need a specific instructional treatment, a treatment that may be different from the instructional treatment needed to enable learners to use language grammatically accurately.

\section{References}

[1] Timpe Laughlin, V., J. Wain, and J. Schmidgall, Defining and operationalizing the construct of pragmatic competence: Review and recommendations., in ETS Research Report No. RR-15-06. 2015, $\begin{array}{lr}\text { Educational Testing } & \text { Service. } \\ \text { http://dx.doi.org/10.1002/ets2.12053: Princeton, NJ. }\end{array}$

doi:

2] Roever, C., Testing of second language pragmatics: Past and future. Language Testing, 2011. 28(4): p. 463-481.

[3] Leech, G.N., Principles of pragmatics. 1983, Essex: Longman.

[4] Rose, K.R., Pragmalinguistics, in The routledge encyclopedia of second language acquisition, P. Robinson, Editor. 2013, Routledge: New York. p. 499-500.

[5] Takahashi, S., Sociopragmatics, in The routledge encyclopedia of second language acquisition, P. Robinson, Editor. 2013, Routledge: New York. p. 597-99.

[6] Celce-Murcia, M., Rethinking the role of communicative competence in language teaching, in Intercultural language use and language learning, E. Alcón Soler and M.P. Safont Jordà, Editors. 2007, Springer: Dordrecht, The Netherlands. p. 41-57.

[7] Murray, N., Pragmatics, awareness raising, and the Cooperative Principle. ELT Journal, 2010. 64(3): p. 293-301.

[8] Leech, G.N., The pragmatics of politeness. 2014, New York: Oxford University Press.

[9] Bardovi-Harlig, K., Exploring the pragmatics of interlanguage pragmatics: Definition by design, in Pragmatics across languages and cultures, A. Trosborg, Editor. 2010, Walter de Gruyter: Berlin. p. 219-259.

[10] Drew, P. and E. Couper-Kuhlen, Requesting - from speech act to recruitment, in Requesting in social interaction, P. Drew and E. Couper-Kuhlen, Editors. 2014, John Benjamins: Amsterdam/ Philadelphia. p. 1-34.

[11] Cohen, A.D., Coming to terms with pragmatics, in Teaching and learning pragmatics: Where language and culture meet, N. Ishihara and A.D. Cohen, Editors. 2010, Pearson Education: Harlow. p. 3-20.

[12] Economidou-Kogetsidis, M., "Please answer me as soon as possible ': Pragmatic failure in non-native speakers' e-mail requests to faculty. Journal of Pragmatics, 2011. 43: p. 3193-3215.

[13] Félix-Brasdefer, J.C., E-mail requests to faculty: E-politeness and internal modification, in Interlanguage request modification, $\mathrm{M}$. Economidou-Kogetsidis and H. Woodfield, Editors. 2012, John Benjamins: Amsterdam. p. 87-118.

[14] Soler, E.A., Mitigating e-mail requests in teenagers' first and second language academic cyber-consultation. Multilingua, 2013. 32(6): p. 779-799.

[15] Szczepaniak-Kozak, A., Interlanguage pragmatics of EFL advanced learners: Insights from a longitudinal study into the development of the speech act of request in the Polish context, in Classroom-oriented research: Reconciling theory and practice, M. Pawlak, Editor. 2016, Springer: Switzerland. p. 197-212.

[16] Woodfield, H., Sociopragmatic variation in native speakers' and ESL learners' requests, in Researching sociopragmatic variability: Perspectives from variational, interlanguage and contrastive pragmatics, K. Beeching and H. Woodfield, Editors. 2015, Palgrave Macmillan: Basingstoke. p. 151-73.

[17] Zhu, W., Polite requestive strategies in emails: An investigation of pragmatic competence of Chinese EFL learners. RELC Journal, 2012. 43(2): p. $217-238$.

[18] Chen, Y.-s., Chinese learners' cognitive processes in writing email requests to faculty. System, 2015. 52: p. 51-62.

[19] Chen, Y.-s., Developing Chinese EFL learners' email literacy through requests to faculty. Journal of Pragmatics, 2015. 75: p. 131-149.

[20] Chen, Y.-s., Understanding the development of Chinese EFL learners' email literacy through Exploratory Practice. Language Teaching Research, 2016. 20(2): p. 165-180

[21] Nguyen, T.T.M., et al., Teaching email requests in the academic context: A focus on the role of corrective feedback. Language Awareness, 2015. 24(2): p. 169-95.

[22] Soler, E.A., Instruction and pragmatic change during study abroad email communication. Innovation in Language Learning and Teaching, 2015.9(1): p. 34-45. 
[23] Kecskes, I., Intercultural pragmatics. 2014, New York: Oxford University Press.

[24] Bardovi-Harlig, K., Pragmatics in second language acquisition, in The routledge handbook of second language acquisition, S.M. Gass and A. Mackey, Editors. 2012, Routledge: New York. p. 147-62.

[25] Félix-Brasdefer, J.C., Pragmatic development in the Spanish as a FL classroom: A cross-sectional study of learner requests. Intercultural Pragmatics, 2007. 4(2): p. 253-86.

[26] Roever, C. and S. Al-Gahtani, The development of ESL proficiency and pragmatic performance. ELT Journal, 2015. 69(4): p. 395-404.

[27] Schmidt, R.W., Interaction, acculturation, and the acquisition of communicative competence: A case study of an adult, in Sociolinguistics and language acquisition, N. Wolfson and E. Judd, Editors. 1983, Newbury House: Cambridge, MA. p. 137-74.

[28] Xu, W., R.E. Case, and Y. Wang, Pragmatic and grammatical competence, length of residence, and overall L2 proficiency. System, 2009. 37: p. 205-216.

[29] Celaya, M.L. and J. Barón, The interface between grammar and pragmatics in EFL measurement and development. European Journal of Applied Linguistics, 2015. 3(2): p. 181-203.

[30] Youn, S.J., Measuring syntactic complexity in L2 pragmatic production: Investigating relationships among pragmatics, grammar, and proficiency. System, 2014. 42: p. 270-87.

[31] Farashaiyan, A. and T.K. Hua, On the relationship between pragmatic knowledge and language proficiency among Iranian male and female undergraduate EFL learners 3L: The Southeast Asian Journal of English Language Studies, 2012. 18(1): p. 33-46.

[32] Trosborg, A., Interlanguage Pragmatics: Requests, Complaints and Apologies. 1995, Berlin: Mouton de Gruyter.

[33] Brown, P. and S.C. Levinson, Politeness: Some universals and language usage. 1987, Cambridge: Cambridge University Press.

[34] Tavakoli, H., A dictionary of research methodology and statistics in applied linguistics. 2012, Tehran, Iran: Rahnama Press.
[35] Blum-Kulka, S. and E. Olshtain, Requests and apologies: A crosscultural study of speech act realization patterns (CCSARP). Applied Linguistics, 1984. 5(3): p. 196-213.

[36] Hahs-Vaughn, D.L., Applied multivariate statistical concepts. 2017, Abingdon: Routledge.

[37] Field, A., Discovering statistics using spss (and sex and drugs and rock ' $n$ ' roll). Third ed. 2009, London: Sage Publication.

[38] Bardovi-Harlig, K., Evaluating the empirical evidence: Grounds for instruction in pragmatics, in Pragmatics in language teaching, K.R. Rose and G. Kasper, Editors. 2001, Cambridge University Press: Cambridge. p. 13-32.

[39] Kecskes, I., How does pragmatic competence develop in bilinguals? International Journal of Multilingualism, 2015. 12(4): p. 419-434.

[40] Kasper, G. and K.R. Rose, Pragmatic Development in a Second Language. 2002, Malden: Blackwell Publishing.

[41] King, B.W. and J. Holmes, Gender and Pragmatics, in The encyclopedia of applied linguistics, C.A. Chapelle, Editor. 2014, John Wiley \& Sons: Malden, MA. p. 1-4.

\section{APPENDIX}

Situation

You are working for a multinational company. The manager of the company, Mr. James Blunder, is an American. He has asked you to send a parcel to another company located quite far away from where you work, so you need a car to deliver the parcel. You can drive, but do not have a car. The manager now is in the U.S. on a business trip. But his car is available for use. Before he left for the U.S., he said that if you needed something you can e-mail him at jblunder@gmail.com. 